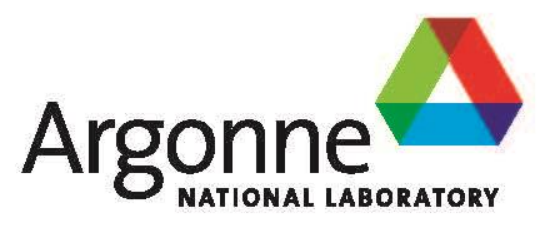

Results of the Six-and-a-Half Day ElectronAccelerator Irradiation of Enriched Mo-100 Targets for the Production of Mo-99

Nuclear Engineering Division 


\section{About Argonne National Laboratory}

Argonne is a U.S. Department of Energy laboratory managed by UChicago Argonne, LLC

under contract DE-AC02-06 CH11357. The Laboratory's main facility is outside Chicago, at 9700 South Cass Avenue, Argonne, Illinois 60439. For information about Argonne

and its pioneering science and technology programs, see www.anl.gov.

\section{DOCUMENT AVAILABILITY}

Online Access: U.S. Department of Energy (DOE) reports produced after 1991 and a growing number of pre-1991 documents are available free via DOE's SciTech Connect (http://Www.osti.gov/scitech/)

Reports not in digital format may be purchased by the public from the

National Technical Information Service (NTS):

U.S. Department of Commerce

National Technical Information Service

5301 Shawnee Rd

Alexandria, VA 22312

unw.ntis.gov

Phone: (800) 553-NTIS (6847) or (703)

605-6000 Fax: (703) 605-6900

Email: orders@ntis.gov

Reports not in digital format are available to DOE and DOE contractors from the Office of Scientific and Technical Information (OST):

U.S. Department of Energy

Office of Scientific and Technical Information

P.O. Box 62

Oak Ridge, TN 37831-0062

unw.osti.gov

Phone: (865) 576-8401

Fax: (865) 576-5728

Email: reports@osti.gov

\section{Disclaimer}

This report was prepared as an account of work sponsored by an agency of the United States Government. Neither the United States Government nor any agency thereof, nor UChicago Argonne, LLC, nor any of their employees or officers, makes any warranty, express or implied, or assumes any legal liability or responsibility for the accuracy, completeness, or usefulness of any information, apparatus, product, or process disclosed, or represents that its use would not infringe privately owned rights. Reference herein to any specific commercial product, process, or service by trade name, trademark, manufacturer, or otherwise, does not necessarily constitute or imply its endorsement, recommendation, or favoring by the United States Government or any agency thereof. The views and opinions of document authors expressed herein do not necessarily state or reflect those of the United States Government or any agency thereof, Argonne National Laboratory, or UChicago Argonne, LLC. 


\section{Results of the Six-and-a-Half Day Electron-} Accelerator Irradiation of Enriched Mo-100 Targets for the Production of Mo-99

by

S. Chemerisov, J. Bailey, T. Heltemes, C. Jonah, R. Gromov, V. Makarashvili, P. Tkac, D. Rotsch, M. Virgo, and G. F. Vandegrift

Nuclear Engineering Division, Argonne National Laboratory

October 2016 



\section{CONTENTS}

ABSTRACT

1 INTRODUCTION

2 DESCRIPTION OF IRRADIATION EXPERIMENTS..................................................... 2

3 BEAM PARAMETERS FOR NORTHSTAR 7-DAY IRRADIATION RUN ……........... 5

4 6.5-DAY IRRADIATION - CHEMICAL PROCESSING …………………………......... 9

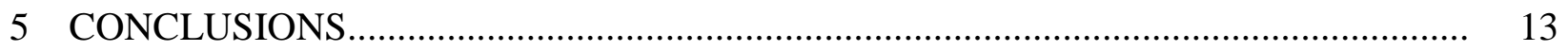

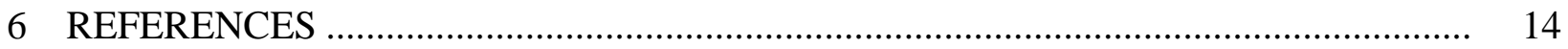

\section{FIGURES}

1 Target and He cooling system arrangement in irradiation room of Argonne linac......

2 Close-up of open half-shell molybdenum disk target and drawings of the target inside lead shielding

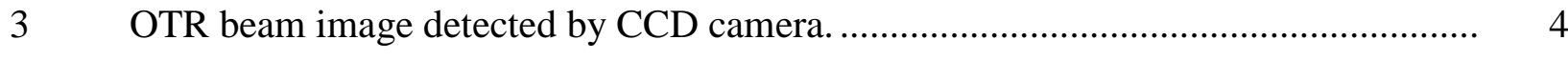

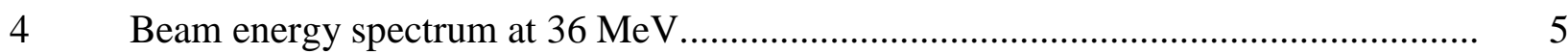

5a Average beam power for 09/10/2015 and 09/11/2015 _.................................... 6

5b Average beam power for 09/12/2015 and 09/13/2015 …................................. 6

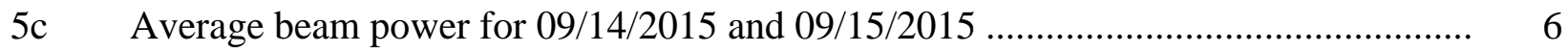

6 End-of-irradiation activity normalized by mass for gold foils at different locations of the dosimeters relative to OTR and IR cameras.

7 Corrosion observed on target housing after irradiation and opened target housing containing 25 disks

8 Photograph of dissolution setup in Big Foot hot cell and solution of $\mathrm{K}_{2} \mathrm{MoO}_{4}$ in $\sim 5 \mathrm{M} \mathrm{KOH}$ that was obtained after filtration and sent to NorthStar.

9 Correlation between experimental and theoretical distribution of ${ }^{99}$ Mo in the target containing six ${ }^{100}$ Mo-enriched and 19 natural Mo disks 


\section{TABLES}

$1 \quad$ Characteristics of six Mo-100 enriched disks used in irradiation............................... 9

2 Total activities obtained based on gamma counting a $1.7 \mathrm{mg}$ aliquot of final Mo solution after dissolving six Mo-100 enriched disks. ........................................ 11

3 Gamma counting results for five natural Mo disks.......................................... 11

4 Activities of $\mathrm{Mo}, \mathrm{Nb}$, and $\mathrm{Zr}$ isotopes for the Mo-98 enriched disk with EOB on $09 / 17 / 15$ at $12: 01$ am 


\title{
RESULTS OF THE SIX-AND-A-HALF DAY ELECTRON-ACCELERATOR IRRADIATION OF ENRICHED MO-100 TARGETS FOR THE PRODUCTION OF MO-99
}

\begin{abstract}
A six-and-a-half day irradiation of enriched Mo-100 target disks was performed by Argonne's electron linac. This report describes the irradiation conditions and the means used to process the targets for shipment to NorthStar Medical Isotopes, LLC, for feed to their RadioGenix ${ }^{\mathrm{TM}}$ technetium generator.
\end{abstract}

\section{INTRODUCTION}

Argonne National Laboratory, in collaboration with Los Alamos National Laboratory (LANL) and NorthStar Medical Radioisotopes, LLC, is developing technology for the production of ${ }^{99}$ Mo via the linac irradiation of ${ }^{100}$ Mo [CHEMERISOV-2014, ROTSCH-2014, GROMOV-2015A]. Argonne is developing the dissolution and processing of the irradiated Mo targets to produce a feed to be used by the NorthStar RadioGenix ${ }^{\mathrm{TM}}{ }^{99 \mathrm{~m}}$ Tc generator [HARVEY2014]. In support of these activities, we have conducted four irradiations of enriched ${ }^{100} \mathrm{Mo}$ targets at the Argonne low energy accelerator facility (LEAF) [CHEMERISOV-2016]. To test

${ }^{99}$ Mo production in conditions relevant to a production facility, we have conducted irradiation of one set of targets for 6.5 days. This is the same duration as NorthStar is planning to irradiate targets at their accelerator facility. After irradiation, the enriched disks were dissolved, and the solution was sent to NorthStar for processing on the RadioGenix ${ }^{\text {TM }}{ }^{99 \mathrm{~m}}$ Tc generator. 


\section{DESCRIPTION OF IRRADIATION EXPERIMENTS}

The target assembly and He-cooling loop for the target were designed by Los Alamos National Laboratory (LANL), and are discussed elsewhere [DALE-2013, -2014]. The main components of the system in the irradiation room are shown in Figure 1. Argonne's low energy and high power electron linac was used as a source of electron beam for the experiments. This machine operates with repetition rate up to $240 \mathrm{~Hz}$ with ultimate beam power up to $110 \mathrm{~J}$ per pulse. Effective beam energy is in the range of 20 to $50 \mathrm{MeV}$. The highest beam energy is about $55 \mathrm{MeV}$. A DC thermal gun produces an electron beam with an amplitude up to $2.0 \mathrm{~A}$ and length of about $6.5 \mu \mathrm{sec}$. Radio frequency (RF) power is provided by two THALES TV2022A klystrons. After acceleration, the beam goes through the transport beamline to an experimental area and is delivered to the entrance window of the target. Steering coils and quads keep the beam in required shape and position [GROMOV-2015A, -2015B]. The molybdenum target consists of 25 metallic disks (1-mm thick by $12-\mathrm{mm}$ diameter) that are separated by $1 \mathrm{~mm}$ gaps for gaseous He cooling (Figure 2). The He gas flow is supplied by a close-loop cooling system. The cooling system consists of a roots blower, a pair of heat exchangers, a mass-flow meter, an oil filter, and piping. The cooling system is pressurized to $280-290$ psig pressure, and the roots blower can provide $\sim 100 \mathrm{~g} / \mathrm{s}$ flow of He gas through the target.

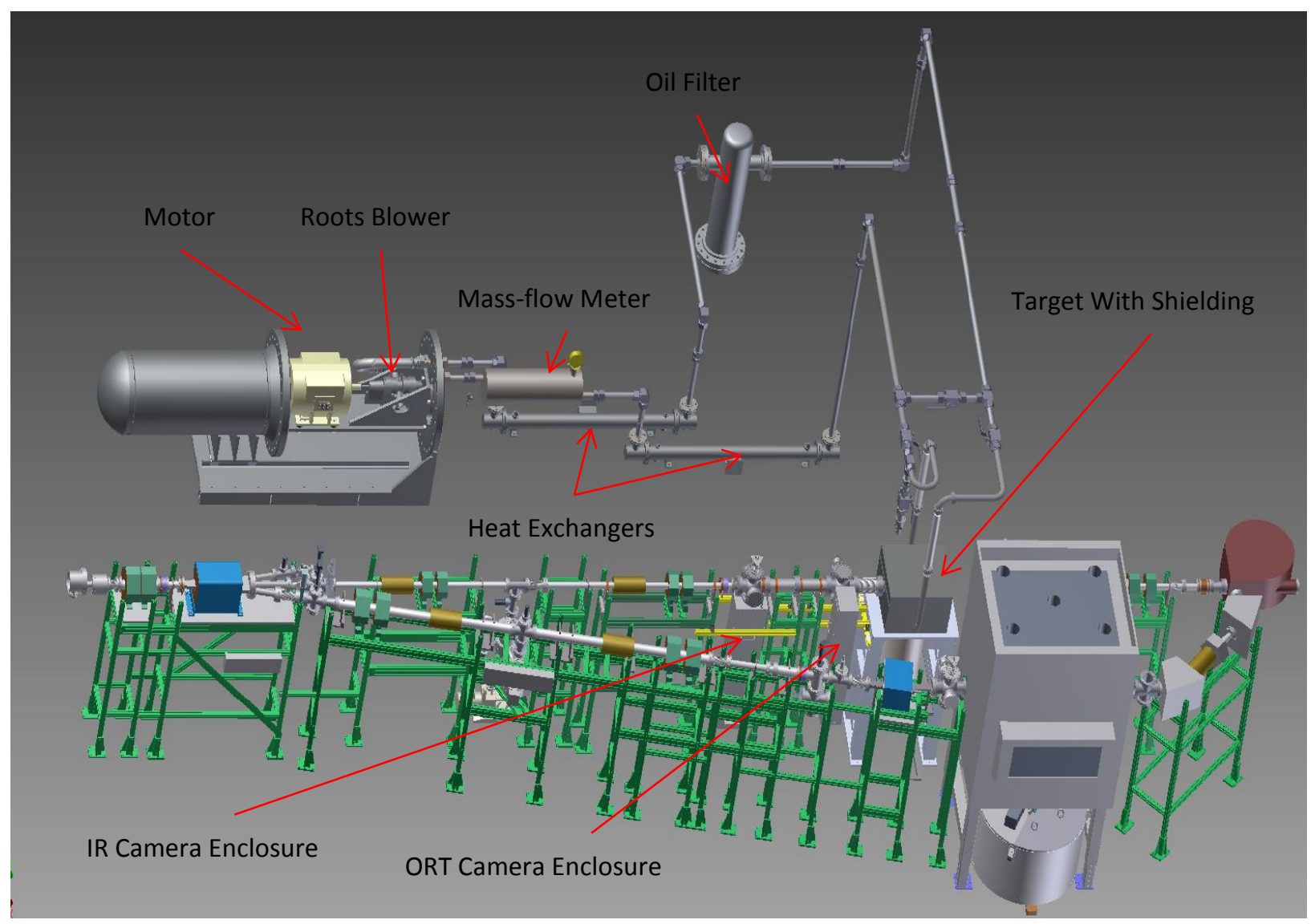

FIGURE 1 Target and He cooling system arrangement in irradiation room of Argonne linac. 


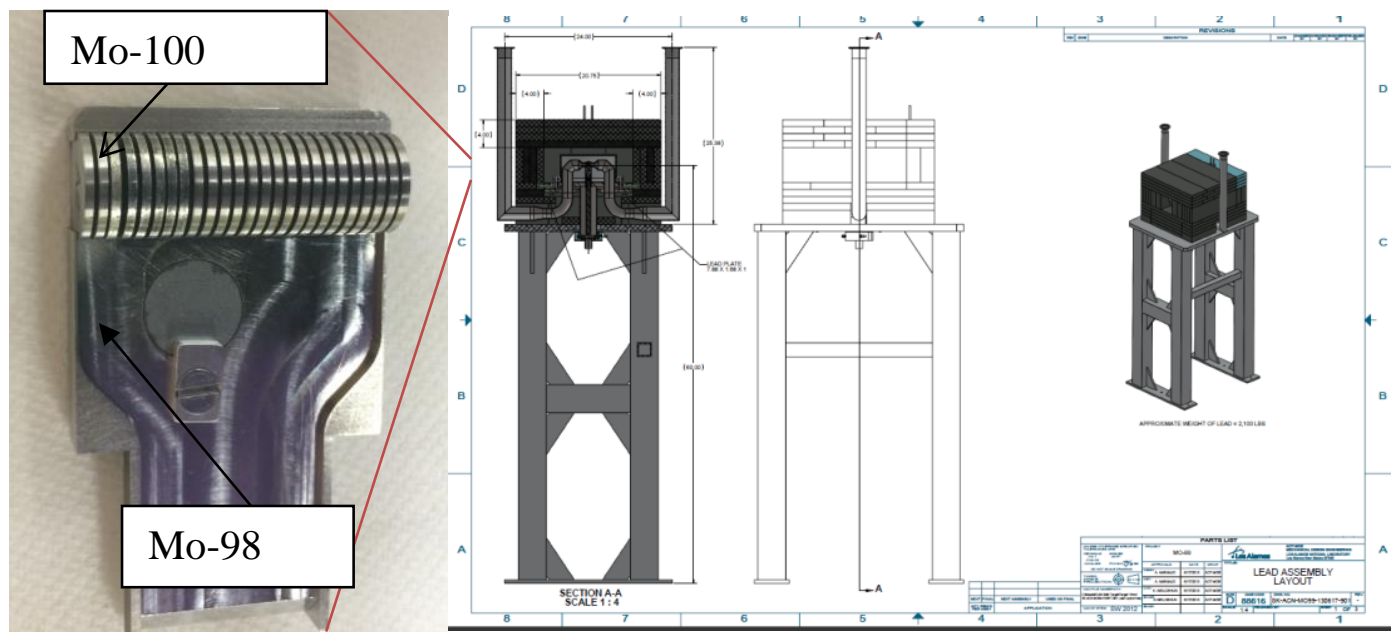

FIGURE 2 Close-up of open half-shell molybdenum disk target and drawings of the target inside lead shielding. Arrows are pointing to ${ }^{100} \mathrm{Mo}$ and ${ }^{98} \mathrm{Mo}$ disks. The ${ }^{98} \mathrm{Mo}$ disk is located on the side of the molybdenum disk target to measure ${ }^{99} \mathrm{Mo}$ production from the $n, \gamma$ reaction.

Optical transition radiation (OTR) is visible light generated when relativistic electrons pass through a boundary between two materials with different characteristics. The OTR image, therefore, provides the location and distribution of the electron beam at the entrance window to the target. The image is captured by a charge-coupled device (CCD) camera equipped with a $180-\mathrm{mm}$ focal length lens. Special care is required to protect the camera from the background radiation. This is accomplished by positioning the camera at a significant distance from the target (approximately $2 \mathrm{~m}$ ) and by shielding the camera with $\sim 15 \mathrm{~cm}$ of lead and 10-15 $\mathrm{cm}$ of borated polyethylene. Lead provides shielding from X-rays, while borated polyethylene provides shielding from neutrons. The camera is located near the floor, and a pair of mirrors is used to provide a line of sight from the camera to the target window. Fine grain alignment is carried out by adjusting the orientation of the first mirror, which is located off-axis inside the beamline vacuum chamber. The camera is synchronized to the electron beam. An Ethernet connection is used to transmit the acquired data to the control system. An example of OTR images of an electron beam on the target is shown in Figure 3.

Indirect thermal measurements of the target, aperture, and beam tube were made with a FLIR $®$ A655sc-7o infrared (IR) camera with high-temperature calibration. The full-window frame rate of the camera is $50 \mathrm{~Hz}$; for these experiments, frame data were saved every $10 \mathrm{sec}$. The camera was positioned at approximately $2.5 \mathrm{~m}$ from the target near the floor. A single mirror was used to provide line-of-sight to the target window. The IR camera was shielded the same way as the OTR camera.

The target insertion, removal, and transport assembly provides safe transfer of the target assembly [CHEMERISOV-2016] that had been irradiated in the linac accelerator beam line to a shielded cell located in an adjacent room. All operations are performed with adequate shielding around the target, and all cart operations are performed manually 

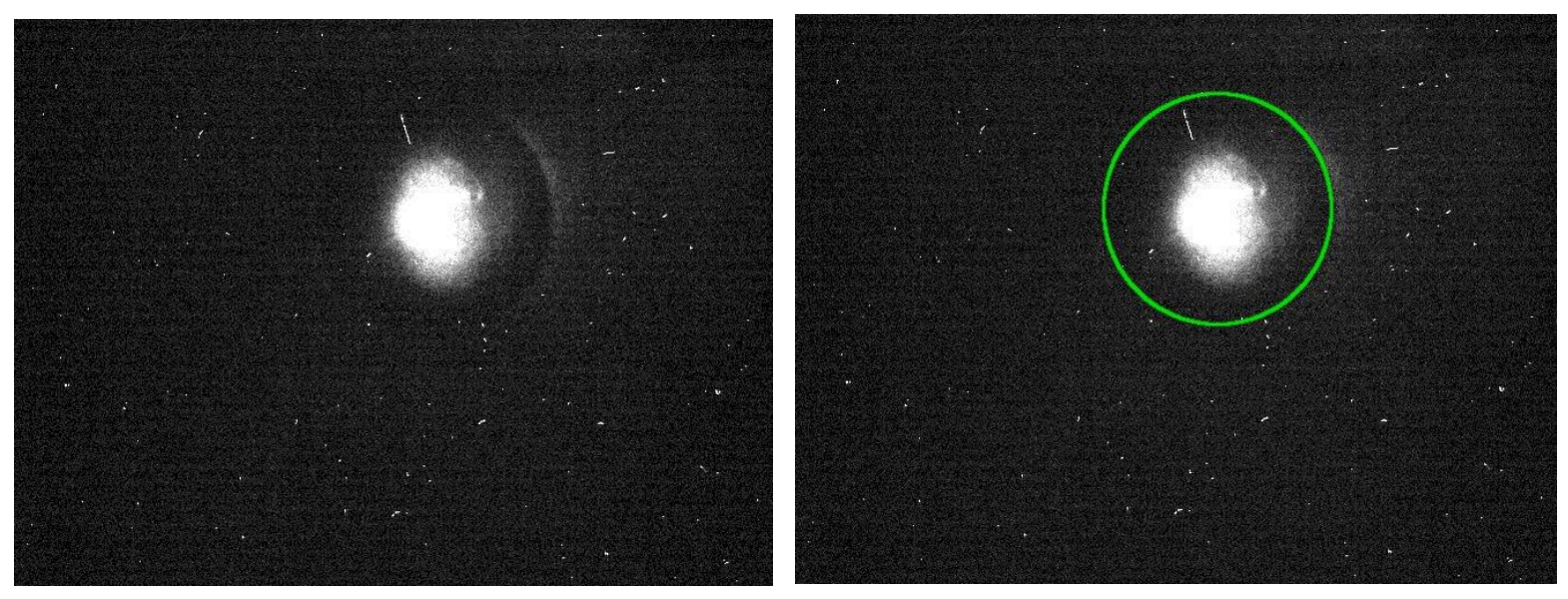

FIGURE 3 OTR beam image detected by CCD camera. Green circle is 12-mm diameter target window area.

During the 24-hr irradiations [CHEMERISOV-2016], significant corrosion of the Mo disks was found to cause flaking of the material from the disks and create unwanted contamination during manipulations and processing. To prevent corrosion, we have implemented a cleaning procedure. In it, the disks and target holder were sequentially washed in isopropanol and hexane. After that, the target was dried and assembled. The assembled target was placed inside a vacuum oven and evacuated for an hour, and then the temperature of the oven was slowly $\left(\sim 1^{\circ} \mathrm{C} / \mathrm{min}\right)$ increased to $160^{\circ} \mathrm{C}$. The target was left in the oven overnight to cool down to room temperature. Before removing the target, the oven was filled with high-purity nitrogen, and the target assembly was removed from the oven and placed on the polyethylene bag filled with dry nitrogen for transport. Within $30 \mathrm{~min}$, the target was installed in the irradiation apparatus, and after that, the target section of the He cooling system was evacuated for several hours, then the cooling system was flushed with high-purity helium.

One of the purposes of the irradiation was to test the performance of the OTR and IR cameras in a high radiation environment. For this testing we surrounded the cameras with X-ray and neutron dosimeters. Each camera installation was equipped with nanoDot OSL dosimeters and thin gold foils for neutron activation.

Before each irradiation, a sample of the helium gas in the cooling system was drawn and analyzed for impurities. The main concern was oxygen concentration due to possible oxidation of the molybdenum disks during irradiation. The helium cooling system was purged until the concentration of oxygen fell below $100 \mathrm{ppmv}$; for all irradiations, the concentration of the oxygen in the system was less than $50 \mathrm{ppmv}$. 


\section{BEAM PARAMETERS FOR NORTHSTAR 6.5-DAY IRRADIATION RUN}

The 6.5-day irradiation run was performed with an electron beam energy of $42 \mathrm{MeV}$. The linac's spectrometer has an upper limit for beam energy measurements of $40 \mathrm{MeV}$; therefore, the beam energy profile tuning was performed at the energy of $36 \mathrm{MeV}$ (Figure 4). After that, the injector current was lowered to reduce beam load for the accelerating structure and to increase the energy gain of the electron beam up to $42 \mathrm{MeV}$ according to the linac's load-line data [CHEMERISOV-2016]. Transverse beam size was tuned to 6 × $6.5 \mathrm{~mm}$.

Beam focusing and alignment were performed with a low beam power (about $0.2 \mathrm{~kW}$ ). After that, the repetition rate was slowly increased to $90 \mathrm{~Hz}$, which corresponds to an average beam current of about $180 \mu \mathrm{A}$ and an average beam power of about $8 \mathrm{~kW}$ (Figure 5a-c) to keep the temperature of the target window below $600^{\circ} \mathrm{C}$. The window temperature was monitored by the IR camera.

Average beam power was monitored during the experimental run with fast current transformers (FCTs). The cause of some variation of the power is due to the injector's thermal cathode instability. Keeping the power in the desired range required periodic correction by the linac operator. In the beginning of the irradiation, the beam power was set at $11.5 \mathrm{~kW}$

(Figure 5a). Due to arcing in second accelerating structure and a degrading vacuum in the target

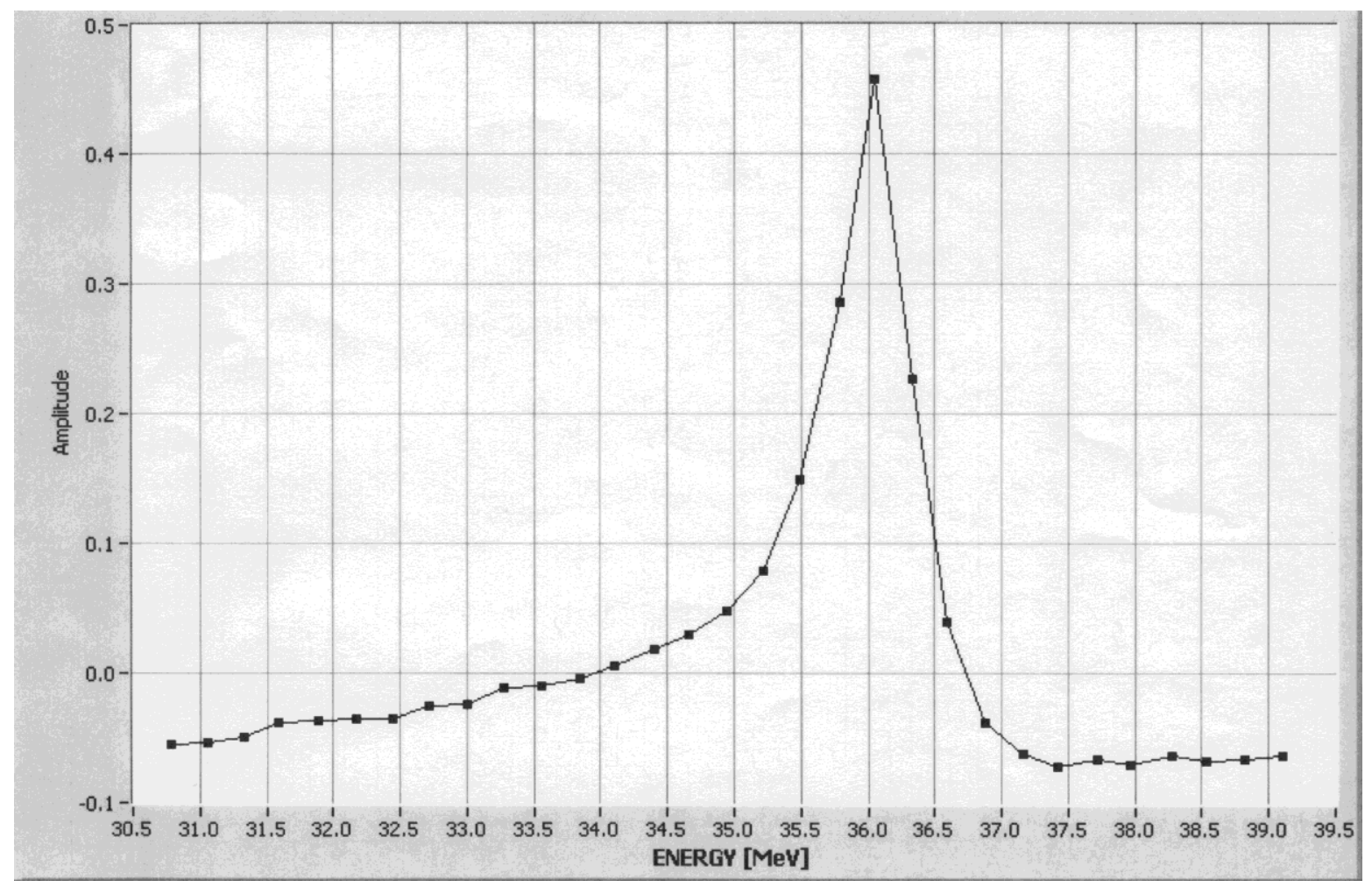

FIGURE 4 Beam energy spectrum at $36 \mathrm{MeV}$. Full width at half maximum (FWHM) of the beam energy spectrum is $\sim 0.8 \mathrm{MeV}$. 


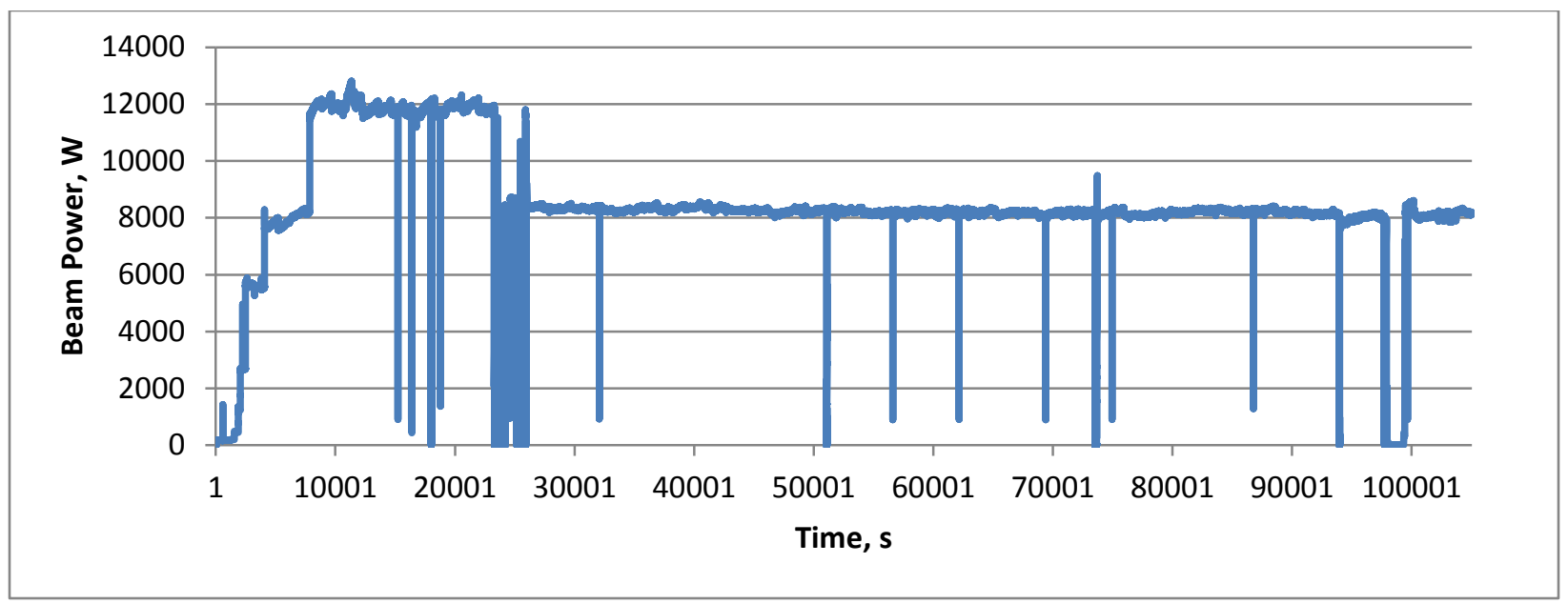

FIGURE 5a Average beam power for 09/10/2015 and 09/11/2015

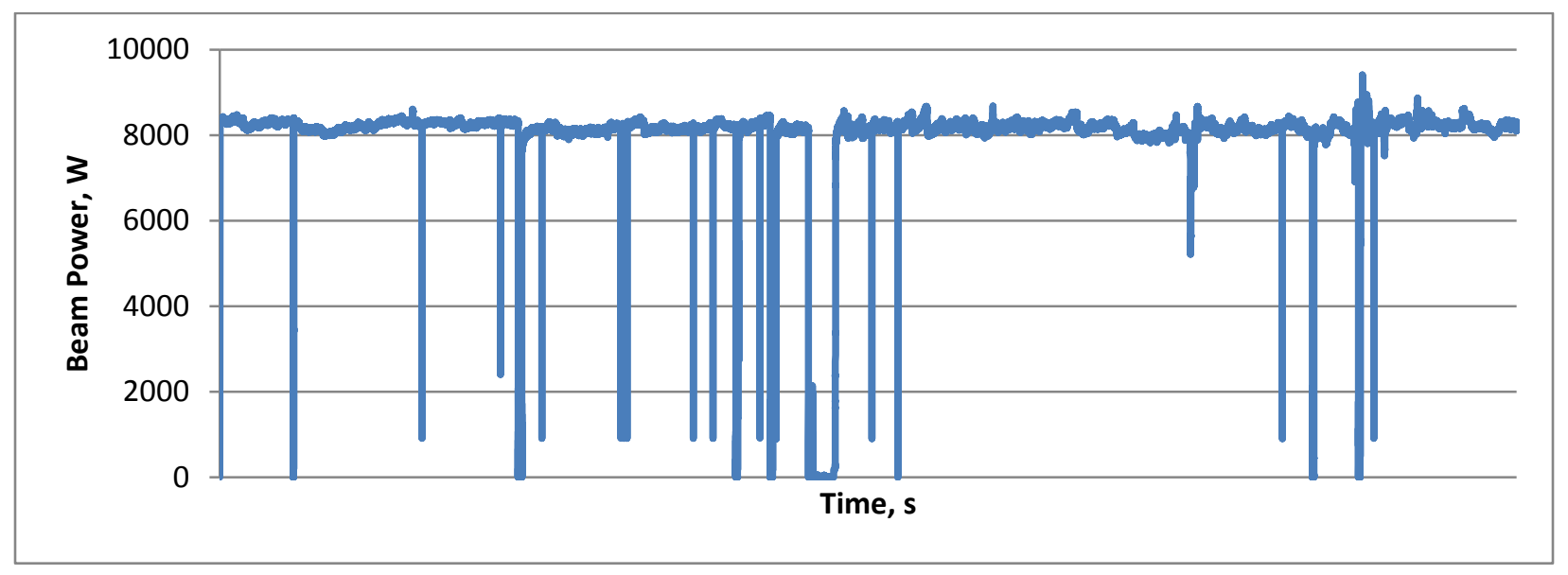

FIGURE 5b Average beam power for 09/12/2015 and 09/13/2015

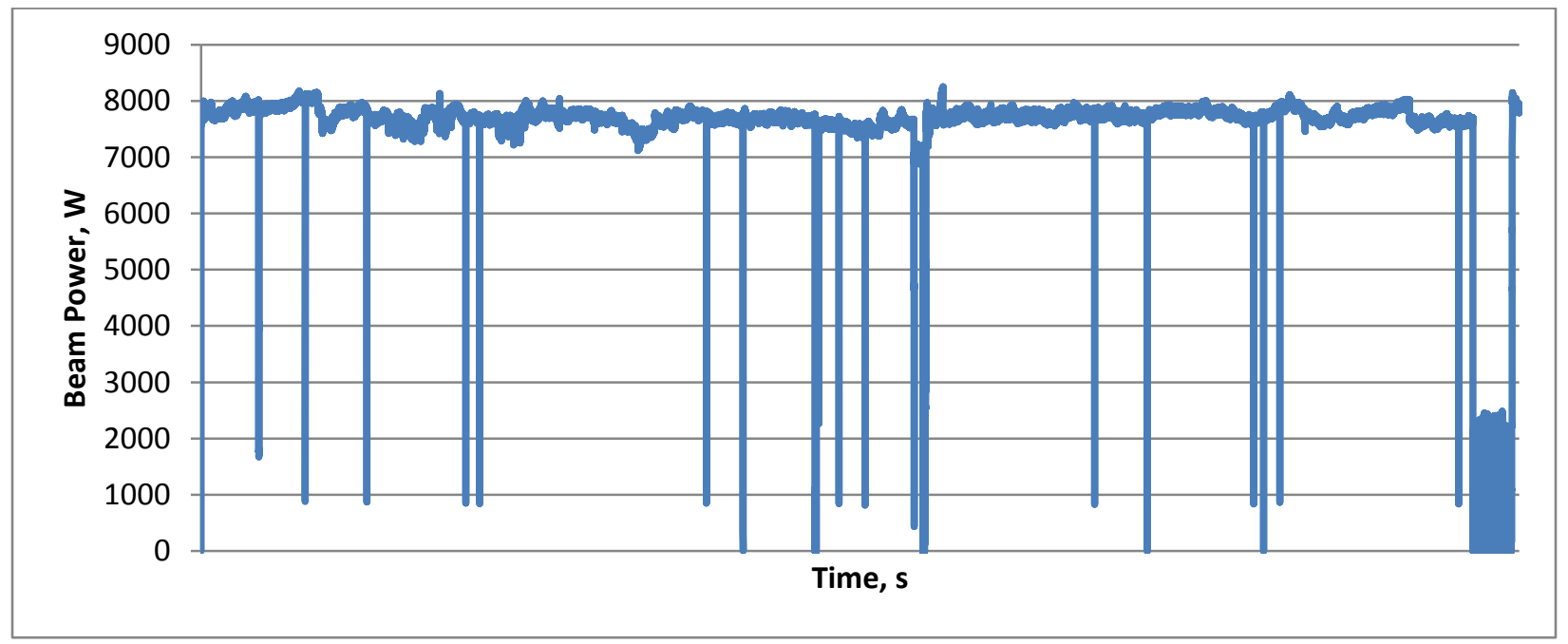

FIGURE 5c Average beam power for 09/14/2015 and 09/15/2015 
area (down to $1.2 \times 10^{-5}$ torr), the irradiation power dropped to $8 \mathrm{~kW}$. Over the duration of the irradiation, we also observed several arcs in accelerating structure \#2 and experienced several beamline vacuum trips (in both the accelerator and irradiation rooms). While recovery of the beam after an accelerating-structure arc usually takes only few seconds, a vacuum trip activates machine protection and closes vacuum valves. Recovering from a vacuum trip usually takes about 10 min to pump down the beamline. On September $15^{\text {th }}$ at 14:12, the linac's control console power breaker was tripped due to overheating, and the machine shut down. It took about one hour to recover the system and put the linac into working condition. We also had several interlock's trips caused by the helium cooling system. Usually, we were able to recover in about one minute.

Two notable effects resulting from the operation of the CCD cameras in a high radiation environment were observed during experimental testing. The first was X-ray induced damage to the CCD array, resulting in loss of pixels. Loss of pixels leads to a darker image and reduced ability to monitor the structure of the beam. The second radiation-induced effect is periodic loss of communication with the camera. This occurred more than fifty times during the irradiation.

The infrared camera was used to monitor and record the surface temperature of the target holder and beam window during irradiation. The IR camera became unresponsive $34 \mathrm{hr}$ after start of irradiation.

Thin $(\sim 100 \mu \mathrm{m})$ gold foils were placed at various locations around the IR and OTR cameras for neutron activation analysis to gain insight into the neutron flux distributions around the cameras. Masses of these foils were in the range of 0.175-0.264 g. Neutron activation analysis (NAA) was performed by gamma counting the activated gold foils after each irradiation using a high purity germanium (HPGe) detector. End-of-bombardment (EOB) activities of the gold foils were determined by measuring the count rate of the $412 \mathrm{keV}$ gamma peak from Au198, which was produced via neutron capture in Au-197, i.e., Au-197(n, gamma)Au-198. The EOB activities were then normalized by mass of the foil and total fluencies of the electron beam ( $\mu \mathrm{A}-\mathrm{h})$ to obtain a quantity proportional to the total neutron flux at those locations. The results from this irradiation and four earlier 24-h irradiations are presented in Figure 6. While the activation of gold foils in the 6.5-day test was much lower than the earlier 1-day tests due to the addition of more borated-polyethylene (BPE), the IR camera still failed during first two days of the irradiation.

The results in Figure 6 allowed us to gauge the effectiveness of the BPE neutron shielding for each test. The initial $4 \mathrm{in}$. $(10 \mathrm{~cm})$ of BPE was increased up to 6-7 in. $(15-18 \mathrm{~cm})$, depending on space availability for the final irradiation. The effectiveness of the BPE is clearly demonstrated by the reduction of the normalized activity in Figure 6. These results together with camera observations indicate that neutron shielding has a significant impact on camera survival and performance. Using Monte Carlo N-Particle Transport (MCNPX) code simulations in combination with NAA results, we concluded that the total energy-integrated neutron fluxes at the camera locations were in the range of $10^{5}-10^{7} \mathrm{n} / \mathrm{cm}^{2}-\mathrm{s}$ for the 24 -hr irradiations and $10^{4} \mathrm{n} / \mathrm{cm}^{2}$-s for the 6.5 -day irradiation. 


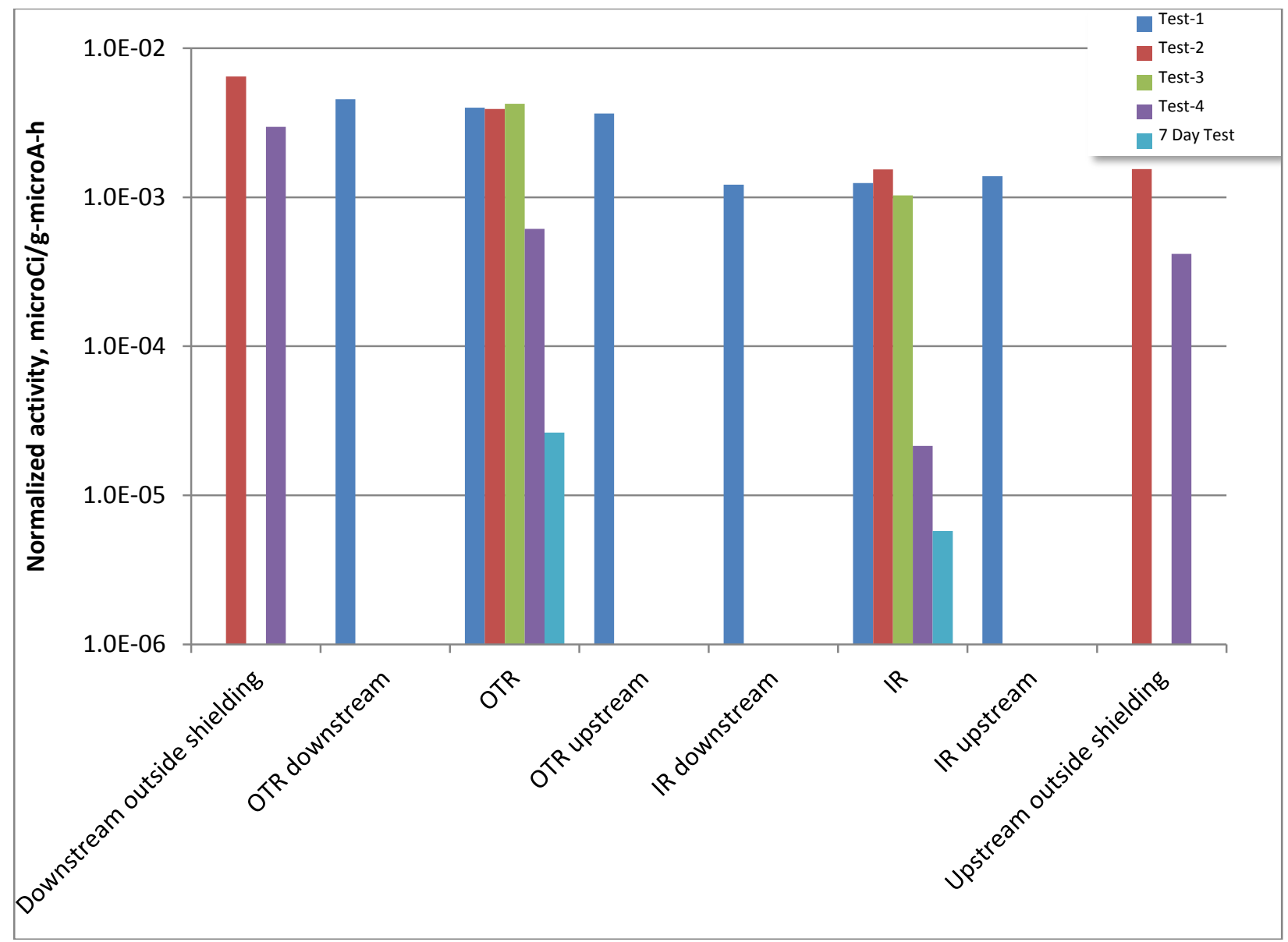

FIGURE 6 End-of-irradiation activity normalized by mass for gold foils at different locations of the dosimeters relative to OTR and IR cameras. Neutron dose for long irradiation is an order of magnitude lower than for the last 24-hr irradiation. 


\section{6.5-DAY IRRADIATION - CHEMICAL PROCESSING}

Six 95.08\% enriched Mo-100 and nineteen natural disks (12 x $1 \mathrm{~mm})$ were irradiated. The characteristics of the six Mo-100 enriched disks are summarized in Table 1. Locations 5-10 were chosen for these disks based on MCNPX calculations predicting the highest production yields with one-sided irradiation (beam striking the target from one side).

TABLE 1 Characteristics of six Mo-100 enriched disks used in irradiation

\begin{tabular}{ccccc}
\hline Disk Location & Mass, g & $\begin{array}{c}\text { Theoretical } \\
\text { Density }\end{array}$ & $\begin{array}{c}\text { Diameter, } \\
\mathrm{mm}\end{array}$ & $\begin{array}{c}\text { Thickness, } \\
\mathrm{mm}\end{array}$ \\
\hline 5 & & & & \\
6 & 1.034 & $86.5 \%$ & 11.99 & 0.996 \\
7 & 1.035 & $86.8 \%$ & 11.99 & 0.993 \\
8 & 1.036 & $86.4 \%$ & 11.99 & 0.999 \\
9 & 1.036 & $86.8 \%$ & 11.99 & 0.994 \\
10 & 1.033 & $87.0 \%$ & 11.99 & 0.989 \\
\hline
\end{tabular}

After irradiation, the target was moved from the linac cell 1 and brought into a hot cell for processing. A very fine orange-brown powder was observed on the target housing upon initial inspection of the target (Figure 7). It is believed that this fine powder was a product of corrosion of the carbon-steel shielding enclosure or the He cooling loop that supported the target assembly. After disassembling the target housing, the fine orange-brown powder was also observed on the Mo disks. The six ${ }^{100}$ Mo-enriched disks (6.21 g) were separated from the natural Mo disks, placed into a $300 \mathrm{~mL}$ Erlenmeyer flask, and dissolved in $100 \mathrm{~mL}$ of $50 \%$ hydrogen peroxide. The dissolution process for sintered Mo disks was previously optimized, and results of the optimization were reported in [TKAC-2012, -2013, -2014]. The water vapor coming from the dissolution reaction was condensed into the collection flask (Figure 8). After complete dissolution, a saturated solution of $\mathrm{KOH}$ was added, and an orange precipitate formed, indicating the presence of iron. To destroy excess peroxide and evaporate water, the solution was heated on a hotplate. After cooling, the solution was passed through a $0.3 \mu \mathrm{m}$ syringe filter, which led to a clear solution with a light orange tint. 


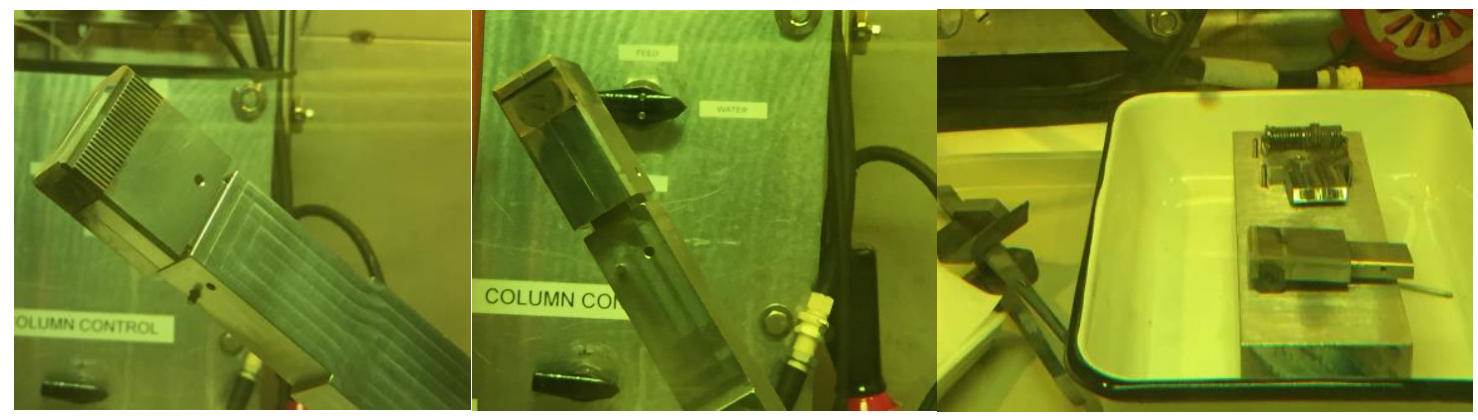

FIGURE 7 Corrosion observed on target housing after irradiation (two images on left) and opened target housing containing 25 disks (right)

During the final addition of water (to adjust the volume to the correct concentration), some of the Mo-99 solution was spilled. The estimated amount of Mo solution lost was $\sim 2-3 \mathrm{~mL}$, which represents $\sim 7-10 \%$ of the total volume. Approximately $26.3 \mathrm{~mL}$ of solution was loaded into a NorthStar RadioGenix ${ }^{\circledR}$ shielded vessel and sent to NorthStar. A small aliquot of this solution was taken for gamma counting. The results from gamma counting are listed in Table 2 . It should be noted that the activities for the $\mathrm{Zr}$ and $\mathrm{Nb}$ radioisotopes listed in Table 2 do not represent the total activities produced at $\mathrm{EOB}$, since most of the activity of $\mathrm{Zr}$ and $\mathrm{Nb}$ was removed during the co-precipitation with Fe and filtration steps.

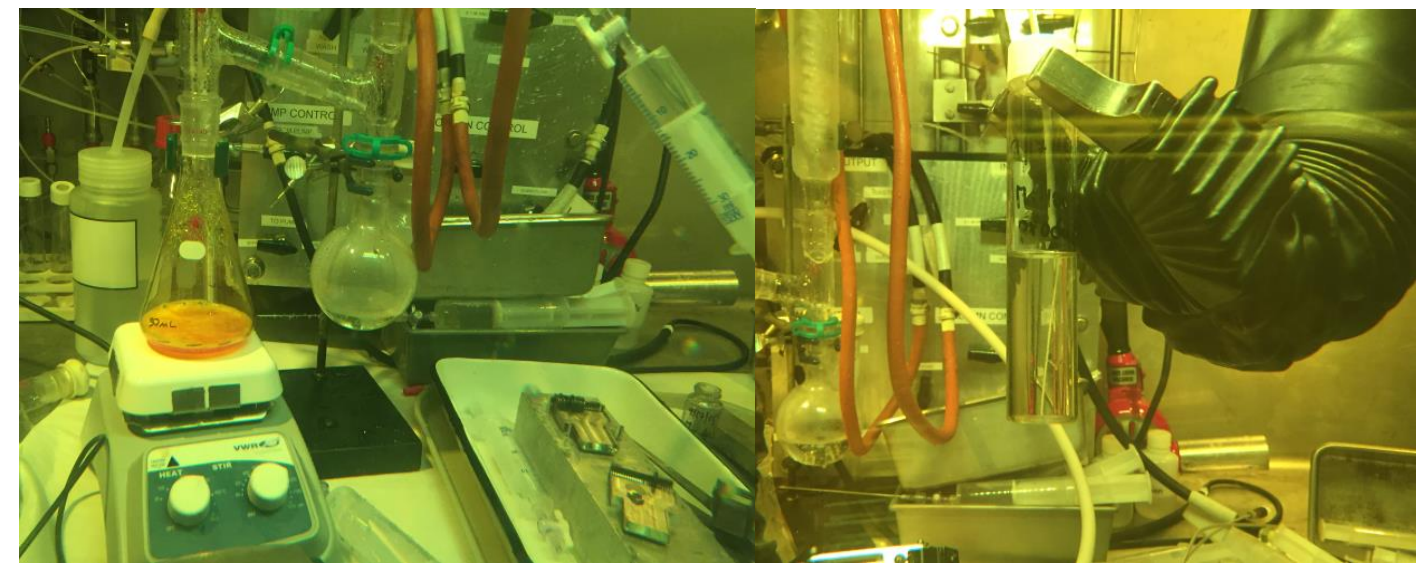

FIGURE 8 Photograph of dissolution setup in Big Foot hot cell (left) and solution of $\mathrm{K}_{2} \mathrm{MoO}_{4}$ in $\sim 5 \mathrm{M} \mathrm{KOH}$ that was obtained after filtration and sent to NorthStar (right) 
TABLE 2 Total activities obtained based on gamma counting a $1.7 \mathrm{mg}$ aliquot of final Mo solution after dissolving six Mo-100 enriched disks. Sample was counted $75 \mathrm{~cm}$ from the detector with $12.5 \%$ dead time. The EOB was 9/17/15 at 12:01 am.

\begin{tabular}{ccc}
\hline Radionuclide & $\begin{array}{c}\text { Total Activity } \\
\text { at EOB, mCi }\end{array}$ & $\begin{array}{c}\text { Uncertainty } \\
1 \sigma\end{array}$ \\
\hline Mo-99 & $1.24 \mathrm{E}+04$ & $3.1 \%$ \\
Nb-92m & $1.36 \mathrm{E}-01$ & $18 \%$ \\
Nb-95m & $1.52 \mathrm{E}+00$ & $26 \%$ \\
Nb-95 & $2.26 \mathrm{E}+00$ & $2.8 \%$ \\
Nb-96 & $3.15 \mathrm{E}+00$ & $4.8 \%$ \\
Zr-95 & $9.94 \mathrm{E}-01$ & $6.4 \%$ \\
\hline
\end{tabular}

Based on the gamma counting results, the total activity of Mo-99 produced at the end of irradiation in six Mo-100 enriched disks was $12.4 \mathrm{Ci}$ (does not include the amount spilled), and $\sim 9.2 \mathrm{Ci}$ of Mo-99 was shipped to NorthStar ( 11.1 Ci at EOB). About 1 month after the irradiation, five natural Mo disks were counted to determine the activity of Mo-99 and other radionuclides. The results are summarized in Table 3.

TABLE 3 Gamma counting results for five natural Mo disks

\begin{tabular}{cccccc}
\hline $\begin{array}{c}\text { Disk } \\
\text { Location }\end{array}$ & $\begin{array}{c}\text { Mo-99 at } \\
\text { EOB, mCi }\end{array}$ & $\begin{array}{c}\text { Nb-92m at } \\
\text { EOB, mCi }\end{array}$ & $\begin{array}{c}\text { Nb-95m at } \\
\text { EOB, mCi }\end{array}$ & $\begin{array}{c}\text { Relative Nb-92m } \\
\text { Activity to Mo-99 }\end{array}$ & $\begin{array}{c}\text { Relative Nb-95m } \\
\text { Activity to Mo-99 }\end{array}$ \\
\hline & & & & & \\
4 & 241.6 & 1.81 & 19.1 & $0.75 \%$ & $7.9 \%$ \\
18 & 125.8 & 0.77 & 9.60 & $0.61 \%$ & $7.6 \%$ \\
21 & 86.9 & 0.55 & 6.66 & $0.64 \%$ & $7.7 \%$ \\
24 & 69.8 & 0.44 & 5.49 & $0.63 \%$ & $7.9 \%$ \\
25 & 61.9 & 0.40 & 4.96 & $0.65 \%$ & $8.0 \%$ \\
\hline
\end{tabular}

The experimental results obtained from gamma counting natural Mo disks compared with calculated data obtained from MCNPX calculations are shown in Figure 9. Total activity obtained after dissolution of six enriched Mo-100 disks was divided based on the activity distribution from MCNPX calculations and allocated to individual enriched disk. Experimentally determined activities from natural Mo disks in locations 18, 21, 24, and 25 were $\sim 76.2 \%$ of the calculated value by MCNPX. Experimental activities in six enriched disks (not including amount spilled) were $\sim 73.7 \%$ of calculated activities. 


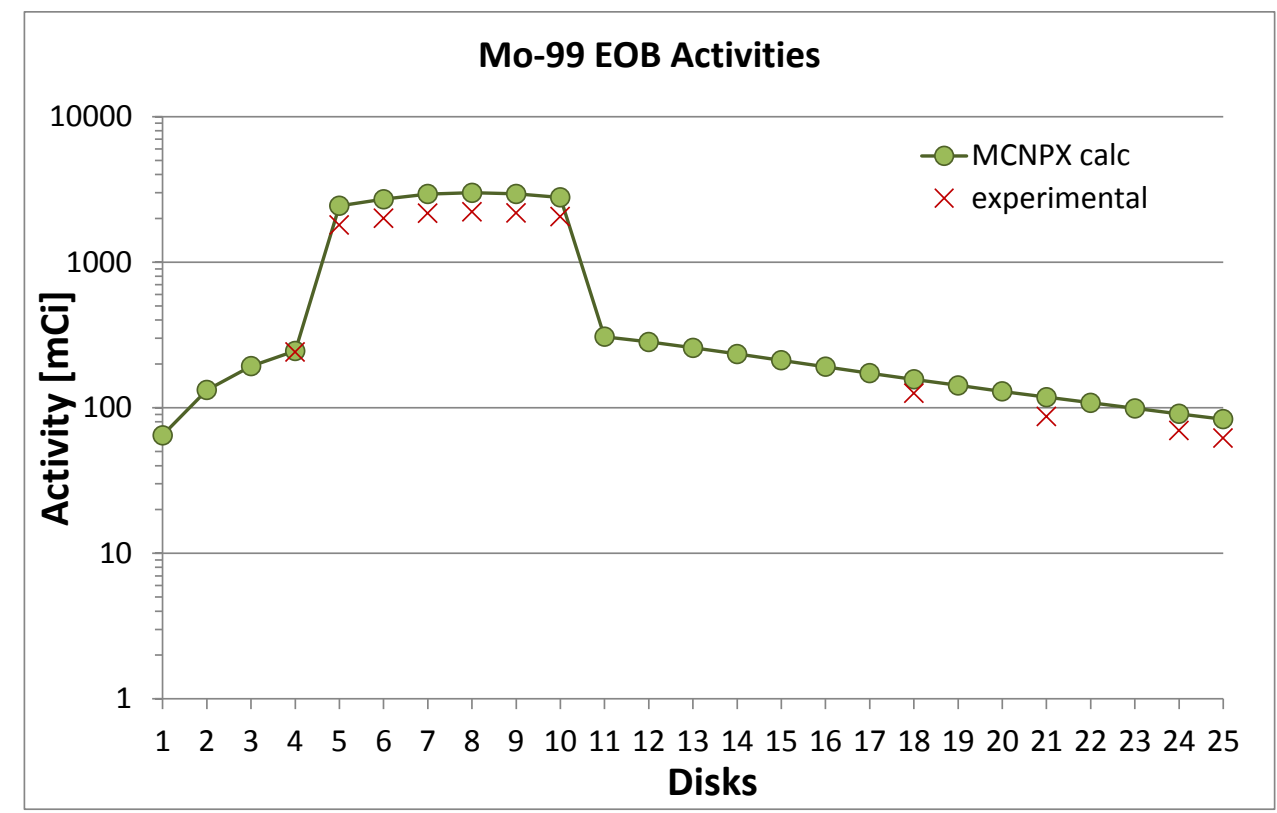

FIGURE 9 Correlation between experimental and theoretical distribution of ${ }^{99}$ Mo in the target containing six ${ }^{100}$ Mo-enriched (locations 5-10) and 19 natural Mo disks

The Mo-98 enriched disk that was not in the direct beam path (Figure 2) was gamma counted, and results are presented in Table 4. This Mo-98 disk was sent to NorthStar for further analysis.

TABLE 4 Activities of Mo, $\mathrm{Nb}$, and $\mathrm{Zr}$ isotopes for the Mo-98 enriched disk with EOB on 09/17/15 at 12:01 am

\begin{tabular}{ccc}
\hline & $\begin{array}{c}\text { Activity at } \\
\text { EOB, } \mu \mathrm{Ci}\end{array}$ & $\begin{array}{c}\text { Uncertainty } \\
1 \sigma\end{array}$ \\
\hline & & \\
Ro-90 & $5.68 \mathrm{E}-01$ & $56.9 \%$ \\
Mo-99 & $2.72 \mathrm{E}-04$ & $3.2 \%$ \\
$\mathrm{Nb}-95 \mathrm{~m}$ & $1.27 \mathrm{E}-01$ & $13.2 \%$ \\
$\mathrm{Nb}-95$ & $1.37 \mathrm{E}-02$ & $2.5 \%$ \\
$\mathrm{Nb}-96$ & $1.48 \mathrm{E}-02$ & $3.5 \%$ \\
$\mathrm{Nb}-97$ & $7.93 \mathrm{E}-01$ & $79.4 \%$ \\
$\mathrm{Zr}-95$ & $4.30 \mathrm{E}-02$ & $4.8 \%$ \\
\hline
\end{tabular}




\section{CONCLUSIONS}

A 6.5-day irradiation of metallic natural and enriched Mo-100 targets was performed at Argonne. The enriched Mo-100 disks were dissolved and sent to NorthStar for testing in its RadioGenix ${ }^{\mathrm{TM}}$ system. Although the irradiation was not flawless, with several small and larger trips, the overall duration of the run mimicked the production schedule for a full-scale irradiation facility. The monitoring of the beam position and target-window temperature using OTR and IR cameras was demonstrated, as was neutron shielding by borated polyethylene. However, use of these cameras in a production environment is still questionable without far more shielding and/or locations significantly further from the beam and target than allowed by the Argonne linac target-room configuration. The ratio of Mo-99 to radioactive impurities in the product from the irradiation was $\sim 1 / 10,000$. 


\section{REFERENCES}

[CHEMERISOV-2014] S. Chemerisov, G.F. Vandegrift, G. Dale, P. Tkac, R. Gromov , V. Makarashvili, B. Micklich, C. Jonah, T. Heltemes, D. Rotsch, K. A. Woloshun, M. Holloway, F. Romero, and J. Harvey, "Overview of Argonne support for Mo-99 medical isotope production: NorthStar Medical Technologies," Proceedings of the Mo-99 Topical Meeting, Washington D.C., June 24-27, 2014, http://mo99.ne.anl.gov/2014/pdfs/papers/S8P4\%20Paper\%20Chemerisov.pdf.

[CHEMERISOV -2016] S. Chemerisov, J. Bailey, T. Heltemes, C. Jonah, R. Gromov, V. Makarashvili, P. Tkac, D. Rotsch, M. Virgo, and G. F. Vandegrift, Results of Four One-Day Electron-Accelerator Irradiations of Enriched Mo-100 Targets for the Production of Mo-99, Argonne National Laboratory Report ANL/NE-16/26 (December 2016).

[DALE-2013] G. E. Dale, S. D. Chemerisov , G. F. Vandegrift , K. A. Woloshun , C. T. Kelsey, IV , P. Tkac , V. Makarashvili , C. D. Jonah , E. R. Olivas , M. A. Holloway , K. P. Hurtle , F. P. Romero , D. A. Dalmas , and J. T. Harvey, "Design and experimental activities supporting commercial U.S. electron accelerator production of Mo-99," AIP Conf. Proc. 1525, 355 (2013).

[DALE-2014] Gregory E. Dale, " Current engineering and design activities at Los Alamos National Laboratory supporting commercial U.S. production of 99-Mo without the use of HEU," presented at the Mo-99 Topical Meeting, Washington D.C., June 24-27, 2014, http://mo99.ne.anl.gov/2014/pdfs/presentations/S8P2\%20Presentation\%20Dale.pdf.

[GROMOV-2015] R. Gromov, J. Bailey, S. Chemerisov, R. Kmak, V. Makarashvili, M. Virgo, and G. F. Vandegrift, "Design of high power beam dump and collimator," Proceeding s of the Topical Meeting on Molybdenum-99 Technological Development, Boston, MA, August 31September 3, 2015, in press.

[GROMOV- 2015] R. Gromov, K. Alford, D. Brown, S. Chemerisov, S. Forknall, J. Gardner, L. Hafenrichter, C. D. Jonah, D. Macrillo, R. Tafoya, K. Wesolowski, and A. Zulpo, "Low energy accelerator facility upgrade and test," Proceedings of $12^{\text {th }}$ International Topical Meeting on the Nuclear Application of Accelerators, November 10-13, 2015, Washington, DC.

[HARVEY-2014] G. P. Messina, G. H. Isensee, J. T. Harvey, and S. D. Moffatt, "New generating system for Tc-99m production," presented at Mo-99 Topical Meeting, Washington D.C., June 24-27, 2014, http://mo99.ne.anl.gov/2014/pdfs/presentations/S3P3\%20Presentaton\%20Harvey.pdf.

[ROTSCH-2014] D.A. Rotsch, P. Tkac, and G.F. Vandegrift, "Argonne chemical-processing activities in support of the development of $\gamma, \mathrm{n}$ production of Mo-99," Proceedings of the Mo-99 Topical Meeting, Washington D.C., June 24-27, 2014, http://mo99.ne.anl.gov/2014/pdfs/papers/S9P7\%20Paper\%20Rotsch.pdf. 
[TKAC-2012] P. Tkac, G. Vandegrift, and J. Harvey, Dissolution of Sintered Mo Disks, Argonne National Laboratory Report ANL/CSE-13/19 (July 2012)

[TKAC-2013] P. Tkac, G. Vandegrift, S. D. Nunn, and J. Harvey, Processing of Sintered Mo Disks Using Hydrogen Peroxide, Argonne National Laboratory Report ANL/CSE-13/44, (September 2013).

[TKAC-2014] P. Tkac and G. F. Vandegrift, Dissolution of Sintered Mo Disks, Argonne National Laboratory Report ANL/CSE-14/26 (September 2014). 
This page intentionally left blank 



\section{Argonne}

Nuclear Engineering Division

Argonne National Laboratory

9700 South Cass Avenue, Bldg. 208

Argonne, IL 60439-4854

www.anl.gov

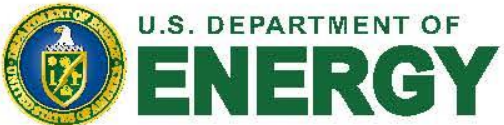

Argonne National Laboratory is a U.S. Department of Energy laboratory managed by UChicago Argonne, LLC 